\title{
Multiple Infections of Helminths in the Stomach and Intestine of Clarias Gariepinus (Burchell, 1822) In Oba Reservoir, Oyo State, Nigeria.
}

\author{
Ajala, Olasunmibo Olumuyiwa ${ }^{1}$ and Fawole, O. Olatunde ${ }^{2}$. \\ ${ }^{1,2}$ Department of Pure and Applied Biology, LadokeAkintola University of Technology, Ogbomoso, Nigeria.
}

\begin{abstract}
The study was carried out in Oba reservoir, ( $8^{\circ} 3^{\prime \prime}$ to $8^{\circ} 12^{\prime \prime} \mathrm{N}$ and $4^{\circ} 6^{\prime \prime}$ to $4^{\circ} 12^{\prime \prime} \mathrm{E}$ in Oyo state, Nigeria.) between August 2011 and November 2013. A total of 246 live fishes (Clarias gariepinus),purchased from local fishermen were examined. In the laboratory, morphometric parameters were measured, sexes determined and fishes were dissected to separate the alimentary system. Parasites recovered were identified and counted; data were subjected to statistical analyses.

Parasites recovered were Procamallanus laevionchus, Paracamallanus cyathopharynx (Nematodes.), Anomotaenia sp., Monobothrium sp., Polyonchobothrium clariae. (Cestodes) and Neoechinorynchus rutili (Acanthocephalan).Using non parametric (NPar), Kolmogorov-Smirnov (K-S) test, infection was significant ( $p$ $=0.05)$ within seasons, and females were more infected than males. Prevalence was $46.34 \%$. Monobothrium sp. had the highest range of infection ( 0 - 32) and intensity (21.98+2.08) while Anomotaenia sp. had the least $(0-$ $1)$ and $(1.00 \pm 0.01)$ respectively. Six parasites were found in the intestine, while four were in the stomach. Fishes of small sizes $(<10 \mathrm{~cm})$ and small weight $(<20 \mathrm{~g})$ were not infected; there was high prevalence in medium and large sized fish and a direct linear relationship exist between length and intensity. Body weight was significant $(K-S ; p=0.05)$ in relation to infection and sex. Multiple infections were common, which showed a positive correlation (Spearman) between most of the parasites except Anomotaenia sp. which showed negative correlation with P. clariae.
\end{abstract}

Key words: Clarias gariepinus, Morphometric, Parasite, Prevalence.

\section{Introduction}

The study of parasites of freshwater fishes in Africa is sporadic and inadequate considering the fish wealth of the continent. Studies in Africa vary considerably from area to area and the parasites are mostly mentioned, as part of the fulfillment of the biology of the host fish species. A concise update of the parasitic diseases of fish in Africa, which described the concurrence and geographical distribution, life cycles, pathology, epizootology and control of the parasites, was published by [1].A checklist of the helminthes parasites of African freshwater fishes was also published [2]. Numerous parasites were associated with Tilapia zilli, Clarias anguillaris and Clarias gariepinus during the study of the biology of the fish species in their natural environments[3], [4] and [5].

From an aquaculture perspective, it is noteworthy that disease and parasite infestation have been poorly studied in Africa due to the low level intensity of aquaculture in the region. At present, the paucity of research in fish diseases in Africa is not seen as a factor that will negatively impact on aquaculture development and as such is not a target research area. The emanating need to culture fishes for protein consumption for the teeming rapidly growing populations in the developing countries like Nigeria have made it necessary to intensify studies on the parasite fauna of the African freshwater fishes, [6].

Fish parasites are important because they affect fish production particularly under culture systems, by decreasing their yield, aesthetic value, marketability, palatability and reproductive potential [7],[8], and if left uncurtailed, may lead to mass mortality of fish, or in some cases, emergence of zoonotic species. They are therefore studied with a view to understanding their population biology and elucidate their life cycles in order to develop an efficient approach of controlling them [9].

The occurrences of helminth parasites in fishes have been studied extensively in various water bodies in Nigeria, with most of the work done primarily from the morphologic and morphometric descriptions, but factors that may limit the ability of parasites to co-exist in multiple infections in a host fish species had in most studies been neglected. This study is focused on the parasite species diversity, the level of coexistence/concurrent infection between them, the factors that might limit this relationship and the effects it has on C. gariepinus. 


\subsection{Study Area}

\section{Materials and Methods}

The study area was Oba reservoir accessed through Ikose (Latitude $8^{\circ} 12^{\prime \prime}$ North, Longitude $4^{\circ} 12^{\prime \prime}$ East), in Ogbomoso North local government area, Oyo state, Nigeria. Oba reservoir was impounded in 1960. The tributaries are Idekun, Eeguno, Akanbi Kemolowo, Omoogun and Yakun streams with a catchment area of 321 sq. km. in Oyo state, Nigeria. The impounded area is 138 hectares of water surface with maximum and minimum depth of 16.36 and 0.83 meters respectively. Two seasons are recognized in the study area - Dry season from October to March and Rainy season from April to September. -.

\subsection{Morphometric measurements}

A total of 246 fishes were examined between August 2011 and November 2013, the fishes were purchased from fishermen, transferred into a plastic container with water and transported to the research laboratory. Transportation was done in the morning to avoid undue stress due to temperature rise. Dead fishes were removed from the collections and examined immediately while the live ones were preserved in a plastic aquaria containing water from the reservoir, and examined subsequently as the investigation progresses. The fish was killed by cervical dislocation. The standard / body length (from the tip of the snout to the end of the caudal peduncle) were measured and recorded for each fish specimen in centimeters with the aid of a measuring board. The weight for each fish was obtained by using a Metler balance. Sexes were determined, the male possess a distinct sexual papilla that is conspicuously located behind the anus, the sexual papillae are absent in females [10].

\subsection{Dissection}

The body of each fish was examined for abnormalities (if any), and placed on a dissecting board. The body cavity was opened with the aid of scissors and the mesentery and connective tissues, connecting loops of the gut and the liver were cut and the organs separated. The gut was then placed in a large Petri dish, stretched out and cut into two regions i.e. the stomach and the intestine. Each section was then placed in a separate labeled dish. The separated gut sections were opened by longitudinal incision to expose the inner surface which was washed with very little quantity of distilled water into labeled test tubes. A drop of the residue was placed on the slide, and observed under $\mathrm{x} 10$ and $\mathrm{x} 40$ objectives of the light microscope for the various parasites, this was repeated until the entire residue has been examined.

\subsection{Recovery of parasites}

Most of the parasites were easily identified by their wriggling movements, parasites found were counted, labeled with the serial number of the fish and placed in physiological saline overnight to allow them stretch and relax. Cestodes, Nematode and Acanthocephalan parasites recovered were stained using the procedure of [11]. Identification of specimen to species level were undertaken and confirmed with the assistance of [8] and [10], who had earlier confirmed the identity of the parasites through the assistance of the British Museum (Natural history), United Kingdom. The terms prevalence and mean intensity were applied as defined by [12], while range refers to zero to maximum number of parasites retrieved from a fish host.

\subsection{Statistical Analysis}

Infection of host by parasites was not normally distributed; significance of parasitic infection was tested using a non-parametric (Npar.) statistical method, (Kolmogorov-Smirnov; K-S test) at p < 0.05 level of confidence and presented pictographically using SPSS version 10.

Spearrman rank correlation was carried out to determine if a pair of parasites in multiple and concurrent infection within hosts was linearly correlated and significant $(\mathrm{p}<0.01)$ using the computer-based SPSS version 15.0

\subsection{Parasites recovered}

\section{Results}

The gastro - intestinal Helminth parasites recovered comprised of two nematodes (Procamallanus laevionchus, Paracamallanus cyathopharynx.), three cestodes (Anomotaenia sp., Monobothrium sp., Polyonchobothrium clariae.) and one acanthocephalan (Neoechinorynchus rutili).

\subsection{Prevalence and intensity of parasites}

A total of 246 Fishes were examined, out of which 114 were infected, giving a prevalence of $46.34 \%$, while Helminth intensity was higher in the intestine than in the stomach. 
Multiple Infections of Helminths in the Stomach and Intestine of Clarias Gariepinus (Burchell...

\subsection{Seasonal distribution of parasites}

There was a significant difference at $\mathrm{p}=0.05$ (K-S test,) in infected C. gariepinus over seasons as more fishes were infected in the dry season than the raining season, (fig. 1).

\subsection{Distribution of parasites}

Monobothrium sp. had the highest range of infection, with a maximum abundance of 60 in a single host specimen and an intensity of $21.98 \pm 2.08$ in the sampled specimens. Anomotaenia sp. had the least range $(0-1)$ and an intensity of $1.00 \pm 0.01$ TABLE 1 . Six parasites were found in the intestine, while only four were in the stomach. Procamallanus laevionchus and Neoechinorynchus rutili, were absent in the stomach. N. rutili was not found in the stomach, but its presence in the intestine varied with season and sex. Intensity in dry season $(0.371 \pm 0.061)$ was higher than raining season (mean $0.042 \pm 0.058)$, and female fishes $(0.503 \pm 0.074)$ were more infected than male, $(0.283 \pm 0.082)$. Infection by $\mathrm{P}$. laevionchus was higher in the raining season $(0.424 \pm .0 .046)$ than dry season $(0.054 \pm .0 .048)$. Generally, the prevalence and intensity of parasitic infection in the stomach and intestine showed significant difference at $\mathrm{p}=0.05$ (K-S test). TABLE 1 showed that the prevalence and intensity of infection was reduced in the stomach, except in Anomotaenia sp. which demonstrated a higher intensity in the stomach than intestine with an abundance of 18 in the stomach. There was a significant difference between infected males and females at $\mathrm{p}=0.05$ (K-S test.). In all the specimens examined, $48.78 \%$ of infected specimens were males while $51.22 \%$ were females.

Table 1. Prevalence, range and intensity of parasites in the stomach and intestine of Clarias gariepinus in Oba Reservoir.

\begin{tabular}{|lcccccccc|}
\hline Parasites & \multicolumn{2}{c}{ Prevalence } & \multicolumn{2}{c}{ Range of } & \multicolumn{2}{c|}{ Nos. of } & \multicolumn{2}{c|}{ Intensity } \\
\hline & \multicolumn{2}{c}{$\boldsymbol{( \% )}$} & \multicolumn{2}{c}{ parasites } & \multicolumn{2}{c|}{ parasites } & \\
\hline & STO. & INT. & STO. & INT. & STO. & INT. & STO. & INT. \\
\hline Anomotaenia sp. & 0.81 & 6.5 & $0-18$ & $0-1$ & 18 & 8 & $1.80 \pm 0.01$ & $1.00 \pm 0.01$ \\
\hline N. rutili & 0.00 & 11.38 & 0 & $0-2$ & 0 & 19 & 0.00 & $1.36 \pm 0.48$ \\
\hline P. laevionchus & 0.00 & 11.38 & 0 & $0-3$ & 0 & 20 & 0.00 & $1.43 \pm 0.51$ \\
\hline P. Clariae & 4.88 & 30.08 & $0-8$ & $0-14$ & 24 & 245 & $4.00 \pm 0.62$ & $6.62 \pm 1.20$ \\
\hline P. cyathopharynx. & 21.95 & 36.59 & $0-28$ & $0-46$ & 197 & 456 & $7.30 \pm 0.84$ & $10.13 \pm 1.85$ \\
\hline Monobothrium sp. & 33.33 & 36.59 & $0-32$ & $0-60$ & 536 & 989 & $13.07 \pm 1.78$ & $21.98 \pm 2.08$ \\
\hline
\end{tabular}

- $\quad \mathrm{STO}=$ Stomach; INT = Intestine.

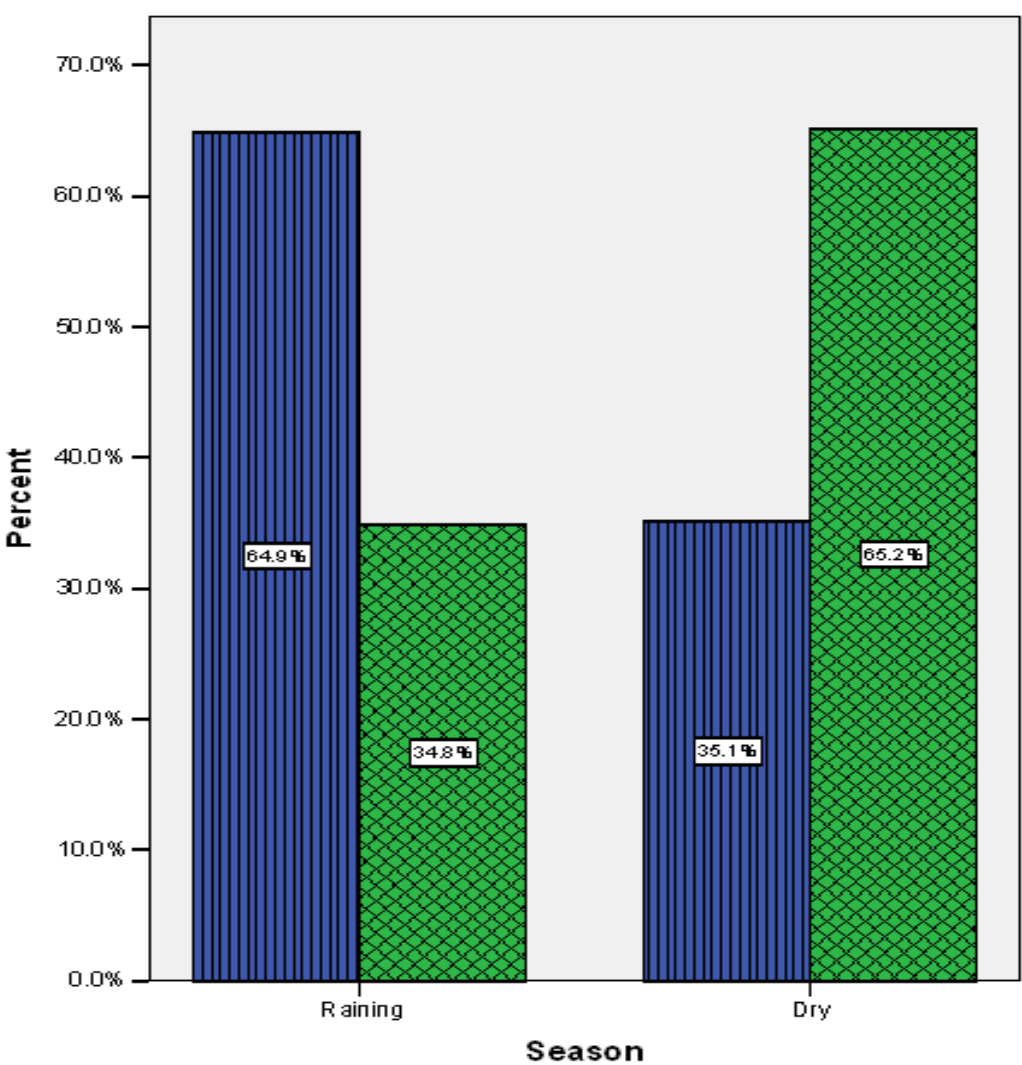

Season

Figure 1: Histogram of the differences in infection between rainy and dry seasons. 


\subsection{Relationship between body length and degree of infection}

There was high prevalence in medium $(20.0 \mathrm{~cm}-29.9 \mathrm{~cm})$ and large sized $(30.0 \mathrm{~cm}-39.9 \mathrm{~cm})$ fish specimen and a direct linear relationship between length and intensity (Fig. 2), the higher the standard length the higher the prevalence and intensity.

Most of the infected specimen had longer body length than uninfected. The mean body lengths for uninfected and infected fishes were $19.63 \mathrm{~cm} \pm 0.35$ and $22.41 \mathrm{~cm} \pm 0.37$ respectively (within sex; male uninfected $18.63 \mathrm{~cm} \pm 0.51$, infected $23.08 \mathrm{~cm} \pm 0.59$; female uninfected $19.02 \mathrm{~cm} \pm 0.61$, infected $24.39 \mathrm{~cm} \pm 0.49$ ); which meant that larger sized fishes were mostly infected in the rainy $(24.72 \mathrm{~cm} \pm 0.46)$ than the dry season $(23.03 \mathrm{~cm} \pm$ $0.410)$.

\subsection{Relationship between body weight (g), sex and degree of infection}

Fig. 3 showed that majority of the sampled specimens infected with helminths were within the same weight groups 20 grammes and 99.9 grammes; however prevalence and intensity was heaviest between 40 and 69.9 grammes weight groups. Infection of C. gariepinus by parasites results in reduction of weight of the fish and generally females have more weight than males in the sampled specimens. Within the same total length range $(20.0 \mathrm{~cm}-39.9 \mathrm{~cm})$, the mean weight of uninfected $(72.27 \mathrm{~g} \pm 2.41)$ samples were considerably higher than infected $(58.62 \mathrm{~g} \pm 1.47)$. Generally, female (uninfected, $76.62 \mathrm{~g} \pm 4.36$; infected, $61.42 \mathrm{~g} \pm 2.73$ ) samples were found to have more weight than their male (uninfected, $66.47 \mathrm{~g} \pm 2.35$; infected, $50.14 \mathrm{~g} \pm 2.47$ ) counterpart.

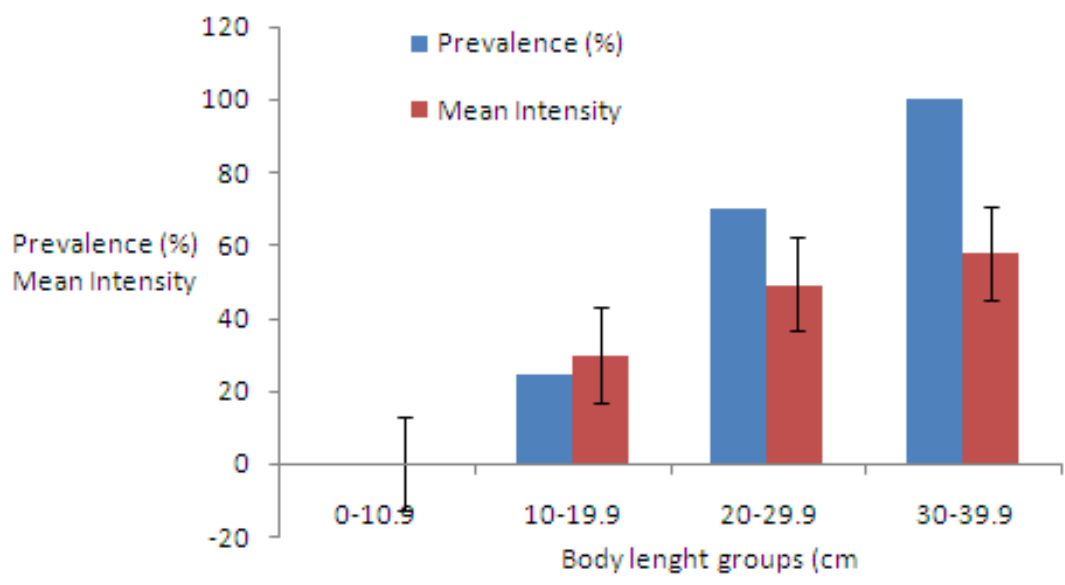

Figure. 2. Relationship between body length (cm), Prevalence (\%) and Mean Intensity with standard error bars.

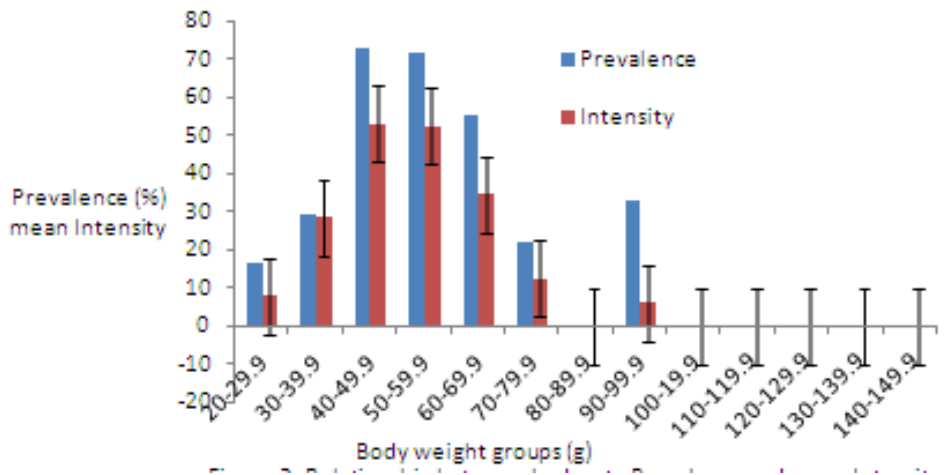

Figure 3. Relationship between body wt (g)., Prevalence (\%) and mean Intensity with standard error bars. 
Multiple Infections of Helminths in the Stomach and Intestine of Clarias Gariepinus (Burchell...

Table 2.Simulation matrix for correlation between multiple infections by parasites in the stomach and intestine of Clarias gariepinus in Oba reservoir.

\begin{tabular}{|l|l|l|l|l|l|l|}
\hline & $\begin{array}{l}\text { Anomotaenia } \\
\text { sp. }\end{array}$ & N. rutili & P. laevionchus & P. clariae & $\begin{array}{l}\text { P. } \\
\text { cyathopharynx }\end{array}$ & $\begin{array}{l}\text { Monobothrium } \\
\text { sp. }\end{array}$ \\
\hline Anomotaenia sp. & 1 & .186 & $.228(* *)$ & -.012 & .063 & .094 \\
\hline Neoechorynchus rutili & .186 & 1 & .083 & $.221(* *)$ & $.284(* *)$ & $.327(* *)$ \\
\hline Procamallanus laevionchus & $.228(* *)$ & .083 & 1 & $.253(* *)$ & $.261(* *)$ & $.187(* *)$ \\
\hline Polyonchobothrium clariae & -.012 & $.221(* *)$ & $.253(* *)$ & 1 & $.835(* *)$ & $.653(* *)$ \\
\hline $\begin{array}{l}\text { Paracamallanus } \\
\text { cyathopharynx }\end{array}$ & .063 & $.284(* *)$ & $.261(* *)$ & $.835(* *)$ & 1 & $.737(* *)$ \\
\hline Monobothrium sp. & .094 & $.327(* *)$ & $.187(* *)$ & $.653(* *)$ & $.737(* *)$ \\
\hline
\end{tabular}

SPEARMAN CORRELATION.

** Correlation is significant at the 0.01 level (2-tailed).

\subsection{Concurrent/multiple parasitic infections in host}

TABLE 2. Showed that multiple infection of host by the identified parasites was common. Ability to successfully co-inhabit with one another in the same host showed a positive correlation coefficient between most of the parasites; it indicated a significant (Spearman correlation; at $\mathrm{p}=0.01$ ) linear relationship between all the parasites except Anomotaenia sp. which showed negative correlation with P. clariae. Apart from this exception, positive correlation among the parasites occurred freely.

\section{Discussion}

\subsection{Prevalence and intensities of parasites in the gut of Clarias gariepinus}

Prevalence of Helminths was higher in the intestine than the stomach, similar to the findings by [13] and [14]. They argued that regional localization in the gut can be attributed to several factors, such as Hydrogen ion concentration, chemotactic response as well as food reserve. [15] reported that helminthes differ in their nutritional and respiratory requirements which may influence their choice of habitat. However the major factor that may have contributed to high parasitic prevalence in the intestine than in the stomach was that most parasites found in the reservoir were Cestodes that lacked digestive system. Obligatorily they had to depend on the digested food in the intestine of their host, which they absorbed through their thin body tegument (that is syncytial and highly absorptive). These parasites may find an acidic medium as presented by the stomach not too conducive to reside.

The high prevalence is further supported by the findings from other studies that reported a high prevalence in the wild population of C. gariepinus [16], [8], [5], [17], [9] and [18]. The varying percentages reported from the West, through the Middle Belt to the far Northern part of Nigeria showed a pattern of decreasing prevalence from Western to Northern Nigeria. This may be attributed to a reduction in the parasite's intermediate host species diversity which may be dependent on types of forest/vegetation available in each geographical ecosystem. Western Nigeria is populated by tropical rain forest, the Middle Belt by savanna woodland/ Sudan savanna and Northern Nigeria by Sahel/dry savanna. Parasite intensity was also higher in the intestine than the stomach for majority of the parasites except Anomotaenia sp, which further confirmed the likely preference of the intestine by the parasites to the stomach.

\subsection{Parasitic infection in relation to sex}

There was a significant difference $(\mathrm{p}=0.05)$ in the infection of male and female in the specimens examined.[19], reported differences in the incidence of infection between male and female fish, and argued that this may be due to differential feeding, either by quantity or quality of food eaten or as a result of different degrees of resistance and infection. The female samples had more weight than their male counterpart, which supported the opinion of differential feeding, either by quantity or quality of food eaten, which predisposes the females to infection. [20] reported that due to physiological state of the female, most gravid females could have reduced resistance to infection by parasites.

\subsection{Effects of seasonal variation on parasitic infection}

The prevalence and intensity was higher in dry season than the rainy season. The factor responsible for this is eutrophication, which often raises parasitism because the associated increase in productivity will increase the abundance of the invertebrate intermediate hosts mostly fresh water crustaceans, [21]. Eutrophication, leads to algal bloom at the peak of rainy season which results in increase in species variety and population of the 
Multiple Infections of Helminths in the Stomach and Intestine of Clarias Gariepinus (Burchell...

parasite's intermediate host, towards the end of the rainy season. This may result in the infection of fishes that fed on them, and thus probably bring about the maturity of the parasites in the fish towards the dry season, depending on the life cycle of individual parasite. Another factor may be a drop in water level in the dry season exposing the invertebrates to their fish predators. [22], reported a similar prevalence of infection in Sarotherodon galilaeus by plerocercoid larvae of pseudophyllidean cestode in Opa reservoir in Ile-Ife, Nigeria, and higher prevalence of infection was also recorded in the dry than the rainy season.

\subsection{Degree of infection of the gut of Clarias gariepinus by parasitic Nematodes}

[23], [24], studied the life cycles of P. laevionchus and P. cyathopharynx and obtained a development of the first three larval stages in Mesocyclops leuckarti. It was observed that the callanidae delivered the first stage larvae, which were ingested by the copepods. The larvae of P. laevionchus reach the third stage after two moults in eight to nine days at temperatures of between $23^{\circ} \mathrm{C}$ and $24^{\circ} \mathrm{C}$. P. cyathopharynxis ia an ovoviviparous camallanid nematode whose larvae are liberated into the gut of the host and passed out with the faeces. The first moult of the parasite takes place in the copepod intermediate host and the last two moults in the fish. It was speculated that the utilization of the copepods as food by the catfishes is responsible for the infection of $\mathrm{C}$. gariepinus by the nematodes. Although [8] did not report the presence of P. cyathopharynx, the occurrence of P. laevionchus at a very low prevalence $(0.83 \%)$ in the intestine was reported.

The intensity of P. cyathopharynx and P. laevionchus found in this study were comparable to the result obtained by [25] who reported a similar occurrence in C. gariepinus. Although both parasites are nematodes, the absence of P. laevionchus in the stomach of specimens recorded from this study may be adduced to differences in physiological tolerance to the acidic medium prevalent in the stomach. Even though P. cyathopharynx was found in the stomach and intestine, preferred the intestine as portrayed by higher intensity and range displayed. [26] suggested that parasitism varied from one aquatic ecosystem to the other and this was influenced by the interplay of mixed biotic and abiotic factors. [10] also reported the presence of P. cyathopharynx in the intestine of C. gariepinus in the Lagos Lagoon, this suggested that P. cyathopharynx also posses physiological adaptability/tolerance to salinity fluctuations.

P. laevionchus intensity was higher in the raining than dry season, which may be deduced from the lifecycle of the parasite as argued by [24] - that the larvae reached the third stage after two moults in eight to nine days at temperatures of between $23^{\circ} \mathrm{C}$ and $24^{\circ} \mathrm{C}$ in the Copepod intermediate host -. This temperature range fell within the raining season so that within nine days of reaching infective stage, fish host feeding on the copepods become infected. Dry season of higher temperature, may not support the development of the parasite larval stages in the invertebrate host, hence its low prevalence in the dry season.

\subsection{Degree of infection by parasitic Cestodes:}

Cestodes formed the bulk of the parasites recovered, [27] also reported cestodes as having maximum prevalence in Clarias batrachus and C. gariepinus. Anatomically, cestodes lack digestive system and obligatorily have to depend on the digested food of their host, which they absorb through their body surfaces, hence they are better found in the part of the host intestine where their nutritional requirements can be met. Host body secretions and immune system may not be a threat as [28] suggested that parasites have an in - built molecular disguise to avoid the host hostile secretions present in its microhabitat.

P. clariae infection showed low prevalence in the stomach, and a much higher value in the intestine with the intensity values following the same trend as the prevalence. Although prevalence was low in the stomach the intensity was high, which suggested P. clariae's preference for both stomach and intestine. This observation was also reported by [8] and [29].

Also [14] reported Anomotaenia sp. and an unidentified species of Procamallanus in C. gariepinus as dominating the stomach only. Anomotaenia sp. a cestode which was expected to be prominent in the intestine than the stomach, as a result of their nutritional requirement (already digested food) seemed to be an exception in that it was also found thriving in the stomach.

Monobothrium sp. expressed the highest range and intensity of all the parasites recovered. Its presence was recorded in the stomach and intestine which suggested a wide physiological adaptation and probably resistance to host defense system. This gave the parasite an opportunity for high prevalence and intensity, though the intensity had a ratio 1:2 (stomach to intestine). The difference in infection between the stomach and intestine could be attributed to high acidity of the stomach since the most resistant parasites occur comfortably there, [30]. Monobothrium sp., distribution was normal for both seasons and sex.

\subsection{Degree of infection by parasitic acanthocephalan}

Neoechinorynchus rutili was found in the intestine of the fish and its prevalence was low. It was not recovered in the stomach which signified the possibility of its not being able to survive in an acidic medium. 
This supported [8], [5] and [25]who reported very low prevalence of the worm in the intestine of its host, while [31] reported the presence of its eggs in the intestine.

\subsection{Body length in relation to parasitic infection and season}

Prevalence and intensity of parasitic infection is directly proportional to body length and there was significant difference $(\mathrm{p}=0.05)$ between infected and uninfected and seasons. Fishes of higher body length were mostly infected. [8],[5] and [25] reported that prevalence of intestinal Helminth infection in C. gariepinus increases with their standard length. A plausible explanation for this may be the change in diet from weeds, seeds, phytoplankton and zooplankton as juveniles to insect larvae, crustaceans, worms and fish at sub-adult and adult stages. These invertebrates may serve as intermediate hosts to some of these parasites, while eutrophication which is seasonal will boost productivity in the rainy season, thereby increasing the population of those invertebrate organisms that served as food for the sub-adult and adult stages.

\subsection{Body weight in relation to parasitic infection, season and sex}

The mean weight of uninfected samples was considerably higher than infected which suggested a weight loss as a result of infection, this was evidenced in [14] who reported the damage inflicted by infestation of two different species of Polyonchobothrium (Polyonchobothrium polypetri and Polyonchobothrium sp.) in the gut of C. gariepinus. They were found blocking and attached firmly to the intestinal lining thus, inducing lesion at site of attachment. This also, likely suggested the absence of infective organisms in the type of diet of the fish while young. [32], also observed heavier fishes as being infected more than low weighted fishes.

Generally female samples were found to have more weight than their male counterpart, which may have predisposed the females to a higher prevalence than their male counterpart due to their feeding habits. Furthermore bigger fishes were recorded more in the rainy season which may be due to the high water level that made it difficult for fishermen to go fishing. This probably gave the fish opportunity to grow coupled with eutrophication that increased invertebrate population and a change in diet on the part of the fish to more nutritive invertebrates.

\subsection{Multiple and concurrent infection by parasites:}

Relationship between Anomotaenia sp. and P. clariae, suggested that Anomotaenia sp. will probably not survive in an acidic medium like the stomach and when found in the intestine with P. clariae an intense competition probably ensued, as a result of same physiological demand. P. clariae may likely have an advantage thereby diminishing the population of Anomotaenia sp. Relationship between Anomotaenia sp. and P. cyathopharynx was not significant though positive but very low, this also applied to Monobothrium sp. and N. rutili. Procamallanus laevionchus will easily co-exist with the remaining parasites but its relationship with Neoechinorynchus rutili, though positive was low and not significant. Both parasites were absent in the stomach. This result likely pointed to similar physiological needs and sensitivity between the two parasites especially to certain existing factors in their immediate micro environment which may instigate fierce competition. Apart from the mentioned exceptions, positive association among the identified parasites occurred freely.

\section{Conclusion}

The gastro - intestinal helminth parasites in the gut of C. gariepinus include two nematodes (Procamallanus laevionchus and Paracamallanus cyathopharynx.) three cestodes (Anomotaenia sp., Monobothrium sp., and Polyonchobothrium clariae.) and one acanthocephalan (Neoechinorynchus rutili). Monobothrium sp. had the greatest intensity of infection while Anomotaenia sp., had the least intensity. Sex and season were found to possibly influence the level of infection while diets also, may likely contribute to the stage at which parasitic infection occurs in C. gariepinus. Fishes of small sizes $(<10 \mathrm{~cm})$ and weight $(<20 \mathrm{~g})$ were not infected. Procamallanus laevionchus and Neoechinorynchus rutili were absent in the stomach maybe as a result of their sensitivity to an acidic environment as presented by the stomach. The cestodes formed the bulk of parasites found in the gut of C. gariepinus. The possibility of multiple and concurrent infection of different species of parasites in a fish was established and poses a health risk of zoonotic transmission to consumers.

\section{References}

[1]. Paperna, I. Parasites, infections and diseases of fishes in Africa: An update. CIFA Technical Paper.31, 1996,157 - 170.

[2]. Khalil, L. F., and Polling, L. Check list of the Helminthes parasites of African Freshwater Fishes (University of the North, Republic of South Africa 1997).

[3]. Eyo, A. A, and Olatunde, A. A.. Protein and amino acid requirements of fish with particular reference to species cultured in Nigeria. In: Fish Nutrition and Fish Feed Technology (Ed.) Fisheries Society of Nigeria (FISON) Lagos, Nigeria. 2001,58 - 71.

[4]. Ovie, S. I, and Ovie, S. O. Fish larval rearing: the effect of pure/mixed Zooplankton and artificial diet on the growth and survival of Clarias anguillaris (Linnaeus, 1758) larvae. J. Aquat. Sci. 17 (1), 2002, 67-73. 
[5]. Olofintoye, L. K. Parasitofauna in some freshwater fish species in Ekiti State, Nigeria. Pakistan Journal of Nutrition. 5(4) 2006, 359 -362 .

[6]. Akinsanya, B., Otubanjo O. A., and Hassan A. A, Helminth Parasites of Malapterurus electricus (Malapteruridae) from Lekki Lagoon, Lagos, Nigeria Journal of Science, 3(3), 2007, 78- 86.

[7]. Ibrahim, C. A. Needet, S. A. Aysel, A. O. Argun and Ercument, G. Ecto-Endoparasite investigation on Mirror carp (Cypriocarpio L., 1758) captured from River Seyhan, Turkey. J. Fish Aquat. Sci., 18: 2001, 87-90.

[8]. Oniye, S. J., Adebote, D. A., and Ayanda, O. I., Helminthes parasites of Clarias gariepinus (Tuegels) in Zaria. Nig. Journal of Aquatics 19 (2), 2004, $71-75$.

[9]. Olufemi D. Owolabi. Endoparasitic helminths of the upside-down Catfish, Synodontis membranaceus in Jebba Lake, Nigeria. International Journal of Zoological Research, 4, 2008, 181-188.

[10]. Akinsanya, B. and Otubanjo, O. A. Helminth Parasites of Clarias gariepinus(Clariidae) in Lekki Lagoon, Lagos, Nigeria. Revista de Biologia Tropical, 54 (1), 2006, 93-99.

[11]. Khalil, L. F. Techniques for identification and investigative helminthology. Helminthology manual, (International Institute of Parasitology, St. Albans, UK. 1991 pp: 156).

[12]. Margolsis, L., Esch, G. W., Holmes, J. C., Kuris, A. M. \&Scad, G. A. The use of ecological terms in parasitology. (Report of an Ad-hoc committee of the American Society of Parasitology). J. Parasitol. 68 (1), 1982, 131-133

[13]. Mohammed, A., Kalu, A.U., Yem, I.Y., Kolndacha, O., Nyaku, R, E. \& Sanni, A. O. Bacteriological quality of Clarias gariepinus (Burchell, 1822) in lake Alau, Borno State, Nigeria. Best Journal 6 (1), 2009, 15 - 18.

[14]. Bichi, A. H. and Yelwa, S. I. Incidence of piscine parasites on the gills and gastro-intestinal tract of Clarias gariepinus at Bagauda fish farm Kano. Bayero Journal of Pure and Applied Sciences, 3(1), 2010, 104 - 107.

[15]. Onwuliri, C. O. E. and Mgbemena, M. O. The parasite fauna of some fresh water fish from Jos, Plateau State, Nigeria Journal of Applied Fisheries and Hydrobiology. 2 1989, 33-37.

[16]. Anosike, J. C., Omoregie, E., Ofojekwu, P. C. \&Nweke, I. E., A survey of Helminth parasites of Clarias gariepinusin Plateau State, Nigeria. J. Aquatic Sci.7, 1992, 39-43.

[17]. Dankishiya, A.S. and Zakari, M. Study on the gastrointestinal helminth parasites of Clarias gariepinus (Tuegels), in Gwagwalada, FCT, Nigeria. The Best Journal.4(2), 2007, $79-81$.

[18]. Ajala, O. O. and Fawole, O. O. A study of Helminth species assemblages at different host scales in Clarias gariepinus (Burchell, 1822 ) as a bio-indicator of aquatic water quality. Conference Proceedings, World Academy of Science, Engineering and Technology (WASET), Singapore. September 2012. 69, 2012, $741-750$.

[19]. Emere, M. C. Parasitic infection of the Nile perch Lates niloticus (L) in River Kaduna. Journal of Aquatic Sciences. 15, 2000, 51 54.

[20]. Emere, M. C. and Egbe, N. E. L. Protozoan parasites of Synodontis clarias (A fresh water fish) in River Kaduna. The Best Journal. 3 , (3) $2006,58-64$.

[21]. Lafferty, K. D. and Kuris, A. M. How environmental stress affects the impacts of parasites. Limnology and Oceanography 44, 1999, 925-931.

[22]. Fawole, O. O. and Akinsanya, B. Prevalence of parasitic infection on Sarothrodon galilaeus (Artedi) from Opa reservoir, Ile-Ife, Nigeria. World Journal of Biotechnology. 2, 2000, $136-140$.

[23]. Moravec, F. The development of Paracamallanus cyathopharynx (Baylis, 1923) Nematoda: Camallanidae. Folia Parasit.21, 1974, 333-343.

[24]. Moravec, F. The development of Procamallanus laevionchus (Wedl, 1862), (Nematoda Camallanidae), VestnikCeskoslovenskeSpolecnostiZoologicke 39, 1975, 23-38.

[25]. Ayanda, O. I. Comparison of parasitic helminthes infection between the sexes of Clariasgariepinusfrom Asa dam Ilorin, northcentral, Nigeria. Scientific Research and Essay 4. (4), 2009, 357-360,

[26]. Williams, H. and Jones, A Parasitic worms of fish. (Taylor and Francis, Bristol, UK. 1994,)

[27]. Singh, H. Kaur, P., Shrivastav, R., Borana, K., Manohar, S. and Qureshi, T. A. Endo-parasitic Helminths of two dominating species of Family Clariidae. Journal of Chemical, Biological and Physical Sciences. 3, (2).2013, 1149-1154

[28]. Buchmann, K. and Lindenstrom, T. Interactions between monogenean parasites and their fish hosts. International Journal of Parasitology.32, 2002, $309-319$.

[29]. Barson, M. and Avenant- Oldewage, A.. Nematode parasites of Clariasgariepinus (Burchell, 1822) from Rietvlei dam, South Africa. Ondestepoort Journal of Vetinary Research, 73, 2006, 87-94 .

[30]. Alfred - Ockiya, J. F. Preliminary survey of parasites of Clarias in Niger Delta Area, Nigeria. Proceeding of the $4^{\text {th }}$ Annual Conference of the Fisheries Society of Nigeria (FISON), Port Harcourt, $26^{\text {th }}-29^{\text {th }}$ Nov 1985; 1985, $210-215$.

[31]. Nnadi E. I. A study of parasitic infections of Clarias gariepinus in natural waters of Owerri, Imo state Nigeria. Int'l Journal of Agric. and Rural Dev. 15 (2) 2012, 976 - 981.

[32]. Omeji, S., Solomon, S.G. and Uloko, C. Comparative study on the Endo-parasitic infestation in Clarias gariepinus collected from earthen and concrete ponds in Makurdi, Benue State, Nigeria. Journal of Agriculture and Veterinary Science 2, (1) 2013, 45-49. 